\title{
Supramolecular co-encapsulation of a photosensitizer and chemotherapeutic drug in cucurbit[8]uril for potential chemophototherapy
}

\author{
Fresia Solis-Egaña ${ }^{1} \cdot$ Nicole Lavín-Urqueta $^{1} \cdot$ Daniel Guerra Díaz ${ }^{1}$. Nory Mariño-Ocampo ${ }^{1}$. Mario A. Faúndez ${ }^{2}$. \\ Denis Fuentealba' ${ }^{1}$
}

Received: 16 November 2021 / Accepted: 14 January 2022 / Published online: 27 January 2022

(c) The Author(s), under exclusive licence to European Photochemistry Association, European Society for Photobiology 2022

\begin{abstract}
Supramolecular strategies as well as combinatorial approaches have been proposed to improve cancer therapeutics. In this work, we investigated the encapsulation of the photosensitizer acridine orange (AO) and the chemotherapeutic drug oxaliplatin $(\mathrm{OxPt})$ in cucurbit[8]uril (CB[8]), and tested their effect both separate and combined on tumoral cells cultivated in vitro. Binding constants and enthalpies of reaction for the AO@CB[8], $(\mathrm{AO})_{2} @ \mathrm{CB}[8]$ and OxPt@CB[8] complexes were determined by isothermal titration calorimetry. In the case of AO, a negative cooperativity for the binding of the second AO molecule was found, in agreement with previous fluorescence titration data. We show herein that the AO@CB[8] complex was effectively incorporated within the cells and showed important phototoxicity, while the OxPt@CB[8] complex was cytotoxic only at long incubation times $(24 \mathrm{~h})$. Pre-treatment of the cells with the OxPt@CB[8] complex for $24 \mathrm{~h}$ inhibited any photodynamic action by the later treatment with the AO@CB[8] complex. However, when both complexes were co-incubated for $90 \mathrm{~min}$, the combined cytotoxicity/phototoxicity was superior to any of the treatments individually. A cooperative effect was identified that added up to an extra $30 \%$ cytotoxicity/phototoxicity. The results point to an interesting system where a photosensitizer and chemotherapeutic drug are co-encapsulated in a macrocycle to develop chemophototherapy applications.
\end{abstract}

\section{Graphical abstract}

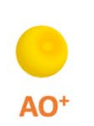<smiles></smiles>

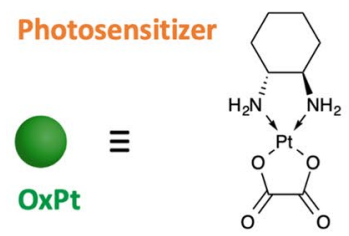

Chemotherapeutic drug

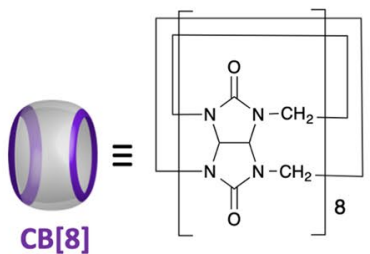

$\mathrm{CB}[8]$

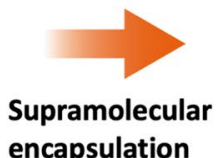

encapsulation
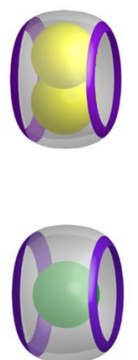

Short incubation period and irradiation

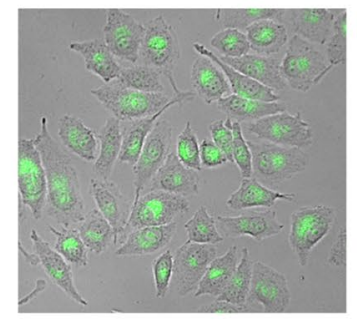

Enhanced tumoral cell killing

Keywords Acridine orange · Oxaliplatin · Cucurbit[8]uril · Supramolecular $\cdot$ Chemophototherapy

Denis Fuentealba

dlfuente@uc.cl

Extended author information available on the last page of the article 


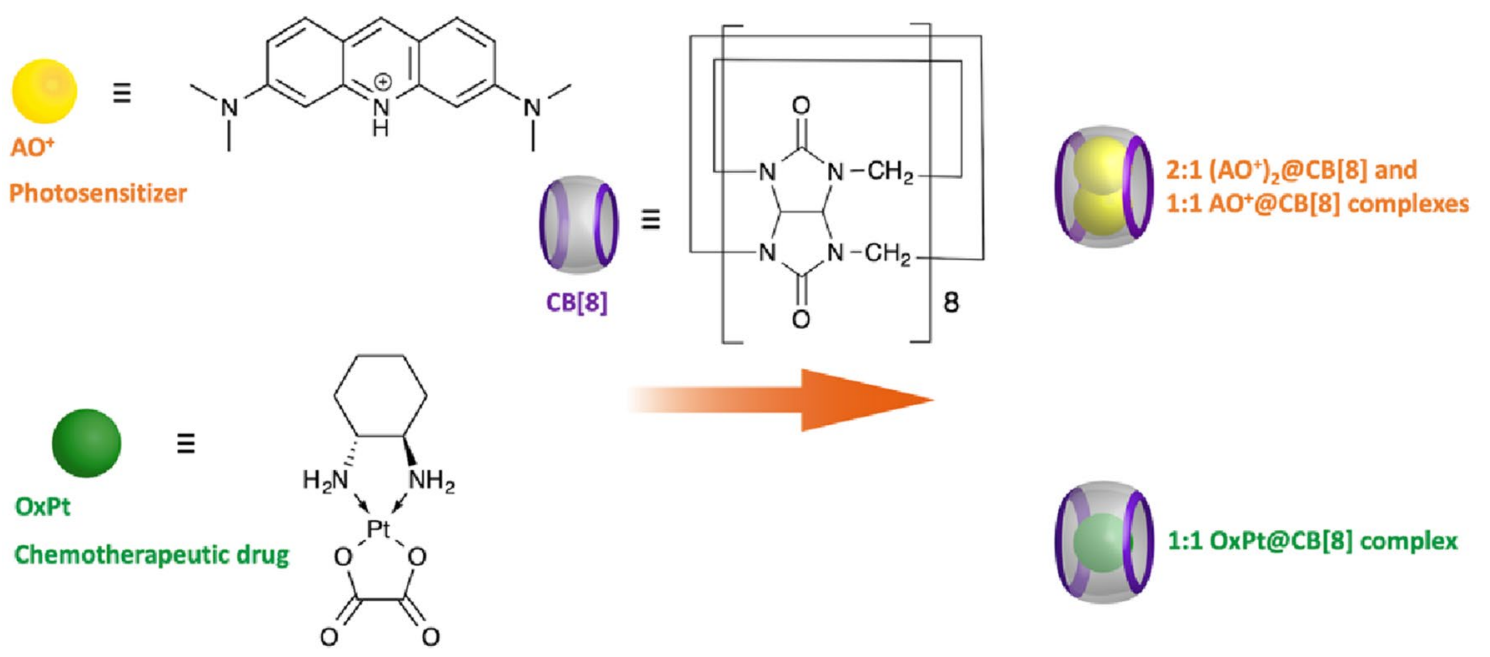

Scheme 1 Structures of photosensitizer AO, chemotherapeutic drug OxPt and CB[8], and their supramolecular encapsulation

\section{Introduction}

Supramolecular chemotherapy has emerged in the last few years as a promising strategy to improve cancer treatment $[1,2]$. The focus of supramolecular encapsulation is to modify the solubility, stability, biodistribution, selectivity and overall performance of chemotherapeutic drugs, while reducing their side-effects [1-5]. Since these supramolecular complexes are governed by non-covalent interactions, this is a broad approach to develop systems that are stimuli-responsive and targeted [6]. Several macrocycles have been used for this purpose including cyclodextrins, calixarenes, metallo-hosts and cucurbit $[n]$ urils [7]. The cucurbit $[n]$ uril family $(\mathrm{CB}[n] \mathrm{s}, n=5-8,10)$ has shown great potential for biomedical applications, due to their high binding affinities, low toxicity, stabilization properties and wide range of guests that can be encapsulated $[8,9]$. On the other hand, supramolecular photosensitizers (light-activated drugs) are the counterpart of chemotherapeutic drugs in phototherapies [10-12]. This type of cancer therapy is more selective, since light can be focused on cancerous tissue sparing healthy tissue [13]. As with chemotherapy, supramolecular encapsulation of photoactive drugs using $\mathrm{CB}[n]$ s has benefits on their solubility and biodistribution, with the extra advantage of controlling their photoactivity and photostability [14-16].

More recently, a combination of both types of therapies termed "chemophototherapy" has been termed as an emerging treatment option for solid tumors [17]. The synergism between these therapies is proposed to enhance tumor regression and prevent drug resistance, leading to a more effective tumor inhibition [13, 17-22]. This concept has been tested both in vitro and in vivo in a preclinical setup with great success [23-25]. However, a combined therapy has the same drawbacks as the individual therapies. Therefore, several drug delivery systems have been studied for that purpose such as liposomes [26, 27], hydrogels [28], micelles [29], and nanoparticles [30-32]. To the best of our knowledge, there are no studies of how macrocyclic supramolecular encapsulation of both the chemotherapeutic agent and photosensitizer would influence their cytotoxicity/phototoxicity toward cancer cells. For that reason, we hypothesized that using a supramolecular approach where the photosensitizer and drug are co-encapsulated in $\mathrm{CB}[n] \mathrm{s}$ would potentially improve PDT outcome in a cooperative manner (Scheme 1).

We chose to encapsulate the chemotherapeutic drug oxaliplatin $(\mathrm{OxPt})$ and the photosensitizer acridine orange (AO) within $\mathrm{CB}$ [8], and test their cooperative behaviour in the photodynamic killing of tumoral cells cultured in vitro. $\mathrm{CB}[8]$ has been less explored for this purpose compared to $\mathrm{CB}[7]$, probably because of its lower solubility in water. However, $\mathrm{CB}$ [8] has certain advantages: (1) it can encapsulate up to two molecules of photosensitizers, doubling the payload; and (2) the binding affinities for some photosensitizers are higher compared to $\mathrm{CB}[7][14,33]$.

The thermodynamics of the binding processes of both molecules were explored and related to the co-existence of the complexes, while the use of different incubation regimes showed the best conditions to achieve enhanced cell cytotoxicity in vitro. 


\section{Methodology}

\subsection{Chemicals}

Oxaliplatin (OxPt), cucurbit[8]uril (CB[8]), acridine orange (AO), and phosphate-buffered saline (PBS) were obtained from Sigma. All other reagents were from the highest purity available. Cell culture media (DMEM) were obtained from Gibco and fetal bovine serum (FBS) from Hyclone. Ultrapure water was used to prepare all aqueous solutions (resistivity of $18.2 \mathrm{~m} \Omega \mathrm{cm}$ ).

Stock solutions of AO $(2 \mathrm{mM})$ were prepared in water $\left(\varepsilon_{491 \mathrm{~nm}}=6.2 \times 10^{4} \mathrm{M}^{-1} \mathrm{~cm}^{-1}\right) . \mathrm{CB}[8]$ was prepared saturated in water and filtered through a $0.22 \mu \mathrm{m}$ filter. The concentrations of both $\mathrm{CB}[n] \mathrm{s}$ were standardized using cobaltocenium with the method described by Kaifer and Yi [34]. OxPt stock solutions were $2.5 \mathrm{mM}$ in water. Stock solutions for cell cytotoxicity experiments were sterile-filtered under a laminar flow hood and later diluted in DMEM.

\subsection{Spectroscopic measurements}

Absorption spectra were measured using a UV-Vis spectrometer from Hewllet Packard 8453. Fluorescence emission spectra were measured on an LS55 PerkinElmer fluorimeter.

\subsection{Isothermal titration calorimetry (ITC)}

Solutions of CB[8] $(25-125 \mu \mathrm{M})$ were titrated with OxPt $(1 \mathrm{mM})$ in water at $25^{\circ} \mathrm{C}$ using a PEAQ-ITC from Malvern. The first injection was of $0.4 \mu \mathrm{L}$ followed by 17 injections of $2 \mu \mathrm{L}$. The reference power was set to $5 \mu \mathrm{cal} / \mathrm{s}, 750 \mathrm{rpm}$ stirring speed, initial delay of $60 \mathrm{~s}$ and injection spacing of $100 \mathrm{~s}$. Titration curves were done in triplicate and the thermodynamic parameters were fitted with the microcal software to the one site-binding model. At $125 \mu \mathrm{M}$ of $\mathrm{CB}$ [8], the complex precipitated upon reaching a 1:1 ratio with OxPt, which shifted the baseline. However, the binding constant was the same as that obtained at lower concentrations of $\mathrm{CB}[8]$. For the case of the $(\mathrm{AO})_{2} @ \mathrm{CB}[8]$ complex, $100 \mu \mathrm{M}$ of $\mathrm{CB}[8]$ were titrated with $\mathrm{AO}(2 \mathrm{mM})$ in $10 \mathrm{mM}$ phosphate buffer $\mathrm{pH} 7$ for comparison with previous fluorescence data [35]. A control of the aggregation of the dye was performed and taken into account in the analysis of the titration curve according to the procedure reported by Buurma and Haq [36]. Data were fitted using I2C-ITC software [37]. For aggregation of AO, an isodesmic stepwise self-aggregation model was used to obtain $K_{\text {agg }}$ and $\Delta H_{\text {agg }}[38,39]$. For the binding of AO to CB [8], two independent sites were considered to fit the data [36].

\subsection{Cell culture studies}

HeLa cells were grown in high-glucose DMEM, with phenol red and supplemented with $10 \%$ FBS and $1 \%$ antibiotic/ antimycotic. Cells were incubated at $37{ }^{\circ} \mathrm{C}$ and a $5 \%$ de $\mathrm{CO}_{2}$ atmosphere with $100 \%$ humidity. Cells were subcultured when needed using the standard trypsin protocol. For phototoxicity experiments, the compounds were incorporated in DMEM without phenol red or/FBS to avoid interference. Cells were counted before seeding using a standard hemocytometer. Cytotoxicity and phototoxicity experiments were performed in 96-well plates. Duplicate plates were used for the dark control and irradiation experiments. In each plate, cells were seeded at 15,000 cell per well and incubated overnight $(n=4-12)$. Culture media was removed by aspiration and rinsed with sterile PBS. The samples containing $0.3 \mu \mathrm{M}$ $\mathrm{AO}, 5 \mu \mathrm{M}$ OxPt, $10 \mu \mathrm{M} \mathrm{CB}[8]$ or mixtures of them were added to the cells. One experiment was performed with $\mathrm{CB}$ [7] instead of $\mathrm{CB}$ [8] for comparison. Two incubation regimes were tried for OxPt, $90 \mathrm{~min}$ and $24 \mathrm{~h}$. In the case of $\mathrm{AO}$, the incubation was done for $90 \mathrm{~min}$ and $15 \mathrm{~min}$ irradiation time at $520 \mathrm{~nm}$ (LED-L16 from Luzchem). After the incubation period, the media were removed and replaced with fresh DMEM. The cells were allowed to develop for another $24 \mathrm{~h}$ and the viability was measured using the MTT assay [40]. Statistical significance was assayed using the GraphPad 9 software with the one-way ANOVA test $(p<0.01)$.

\subsection{Cell uptake}

HeLa cells were seeded $24 \mathrm{~h}$ prior to the experiment at a concentration of $2.5 \times 10^{5} \mathrm{HeLa}$ cells/well in 6-well plates (70-80\% confluency). After removal of the media, cells were incubated for 90 min with $\mathrm{AO}, \mathrm{AO} @ \mathrm{CB}[8]$ or $\mathrm{AO} @ \mathrm{CB}[8]$ plus OxPt@CB[8] at the same concentrations mentioned above (Sect. 2.5). After washing with HBSS, trypsinization and centrifugation, the pellet was resuspended in $2 \%$ SDS and incubated overnight at $37^{\circ} \mathrm{C}$. The concentration of AO taken up by $10^{6}$ cells was determined using a standard fluorescence calibration curve.

\subsection{Fluorescence microscopy}

Cells were prepared in the same conditions as described above for phototoxicity experiments. After $90 \mathrm{~min}$ incubation of the different compounds, images were captured in each well using a Cytation 5 cell imaging multimode reader from Biotek. Images were captured using the $10 \times$ objective for bright field and GFP fluorescence (ex 469/35 nm and em $525 / 39 \mathrm{~nm}$ ) under the same setup conditions. Images from different channels were merged and colored green using Image J. 


\section{Results and discussion}

We chose $\mathrm{AO}$ as a photosensitizer building on previous work by us and others where the photophysics/photochemistry of the AO@CB[8] and (AO) @ $@$ CB[8] complexes were studied [33, 35, 41-43]. Additionally, these complexes have been proposed to be stable inside living cells based on fluorescence measurements [43]. First, we determined the stepwise association of $\mathrm{AO}$ to $\mathrm{CB}[8]$ by ITC, which is not trivial due to the aggregation of the dye in aqueous media. The aggregation constant for the dye $\left(K_{\mathrm{agg}}\right)$ by this method was determined to be $9000 \mathrm{M}^{-1}$ with a $\Delta H_{\text {agg }}$ of $-8 \mathrm{kcal} \mathrm{mol}^{-1}$ (see Fig. S1 in the supplementary information), and these values are consistent with the literature [44]. Following the procedure reported by Buurma and Haq [36], we determined stepwise binding constants for the first and second $\mathrm{AO}$ molecules bound to $\mathrm{CB}[8]$ using the model depicted in Fig. 1A. The values' parameters obtained were $(1.6 \pm 0.6) \times 10^{7} \mathrm{M}^{-1}$ with a $\Delta H_{1}=-(12.8 \pm 0.1) \mathrm{kcal} \mathrm{mol}^{-1}$, and $(3 \pm 1) \times 10^{5} \mathrm{M}^{-1}$ with a $\Delta H_{2}=-(3 \pm 1) \mathrm{kcal} \mathrm{mol}^{-1}$, for the first and second $\mathrm{AO}$ molecules bound to $\mathrm{CB}[8]$, respectively (see Fig. S2 in the supplementary information). These binding constants are one order of magnitude lower than previously reported using fluorescence measurements [35]. It must be pointed out that these techniques measure fundamentally different phenomena. While ITC measures are heat absorbed or evolved upon binding in the ground state, fluorescence measures the emission of the different species in the equilibrium in the excited state [45]. A similar behaviour was reported for a peptide bound to $\mathrm{CB}[8]$ when comparing both techniques [35]. These data confirm the negative cooperativity found previously for this system by fluorescence measurements [35]. It must be pointed out that depending on the concentrations of the photosensitizer and macrocycle, both $1: 1$ and 2:1 complexes can be present in solution. Nonetheless, at high concentrations of $\mathrm{CB}[8]$ with respect to $\mathrm{AO}$, the 1:1 complex will be favored [35].

On the other hand, for the chemotherapeutic drug, we chose OxPt, which is approved for the treatment of colorectal cancer [46]. This drug has been previously encapsulated inside CB[7], which enhances its stability and selectivity for tumoral cells, while reducing its toxicity to non-neoplastic cells [2, 3, 47-49]. Recently, similar results have been reported for the drug heptaplatin with $\mathrm{CB}$ [7] [50]. However, no experimental studies have been reported for OxPt and $\mathrm{CB}[8]$ in spite of the fact that this complex was predicted to

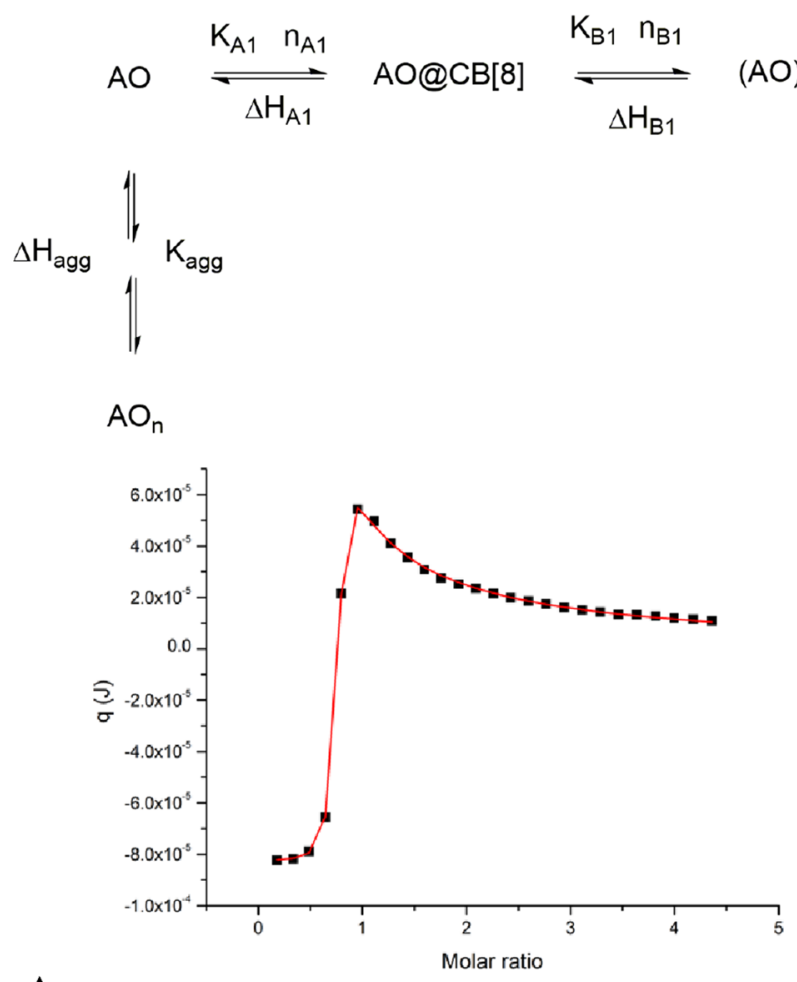

A

Fig. 1 ITC analysis for A stepwise binding of AO to $\mathrm{CB}[8]$ in $10 \mathrm{mM}$ phosphate buffer $\mathrm{pH} 7$ at $25^{\circ} \mathrm{C}$. Data fitted using the I2C-ITC software to the model depicted. B binding of OxPt to $\mathrm{CB}[8]$ in water at $25^{\circ} \mathrm{C}$. Data fitted using the Microcal software with the "one set of sites" model
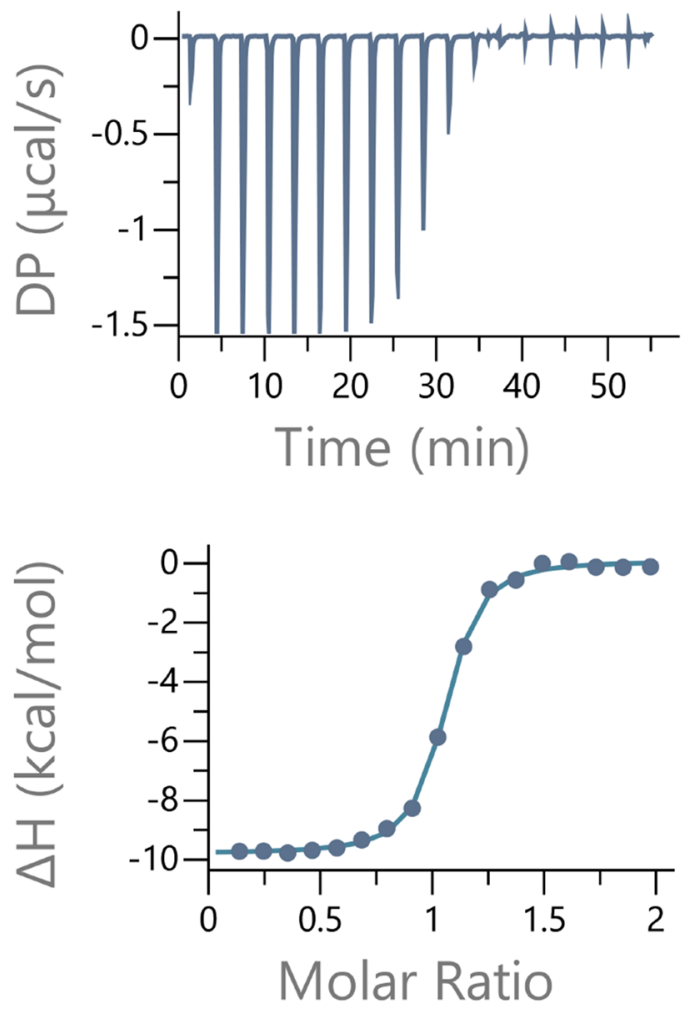
be formed by theoretical calculations [51,52]. Therefore, we investigated the formation of this complex by ITC. We found that $\mathrm{OxPt}$ does bind quite strongly to $\mathrm{CB}[8]$ with a $1: 1$ stoichiometry and a binding constant of $(2.5 \pm 0.1) \times 10^{6} \mathrm{M}^{-1}$ and $\Delta H$ of $-(8.2 \pm 0.5) \mathrm{kcal} \mathrm{mol}^{-1}$ (Fig. 1B). This value is comparable to the binding constants reported for the OxPt@ $\mathrm{CB}$ [7] complex, which are $2.3 \times 10^{5} \mathrm{M}^{-1}$ in Tris buffer [47] and $2.89 \times 10^{6} \mathrm{M}^{-1}$ in PBS [3], $1.25 \times 10^{7} \mathrm{M}^{-1}$ in water [53], and $5.29 \times 10^{5} \mathrm{M}^{-1}$ in cell culture media [53].

Since the binding constant for the first molecule of AO to $\mathrm{CB}[8]$ is six times higher than for $\mathrm{OxPt}$, and due to the presence of excess $\mathrm{CB}[8]$, we expect that the $\mathrm{AO} @ \mathrm{CB}[8]$ complex would remain stable in the presence of OxPt. Indeed, at a low concentration of $\mathrm{OxPt}(5 \mu \mathrm{M})$, the absorption spectra of the AO@CB[8] complex showed only minor changes at $492 \mathrm{~nm}\left(\lambda_{\max }\right.$ for $\left.\mathrm{AO}\right)$, indicating a negligible degree of displacement of AO from the cavity of the macrocycle (Fig. 2A). This result shows that it is possible to have both complexes in solution at these low concentrations.

Nevertheless, when the concentration of OxPt was increased up to $80 \mu \mathrm{M}$ a marked increase in the fluorescence intensity and a characteristic blue shift of the emission spectra were observed, which are consistent with the competitive displacement of $\mathrm{AO}$ from the cavity of $\mathrm{CB}[8]$ (Fig. 2B) [35]. The changes in fluorescence emission observed upon increasing the OxPt concentration (inset in Fig. 3) are attributed to the difference in the fluorescence quantum yields of the free and complexed AO species, being higher for the former [35, 43]. It must be noted that the displacement is only significant at high concentrations of the $\mathrm{OxPt}([\mathrm{OxPt}] /$ [AO] 200 to achieve $~ 50 \%$ displacement).

To test the possible cooperative cytotoxic effect of both $\mathrm{CB}[8]$ complexes in tumoral cells, first, we determined the

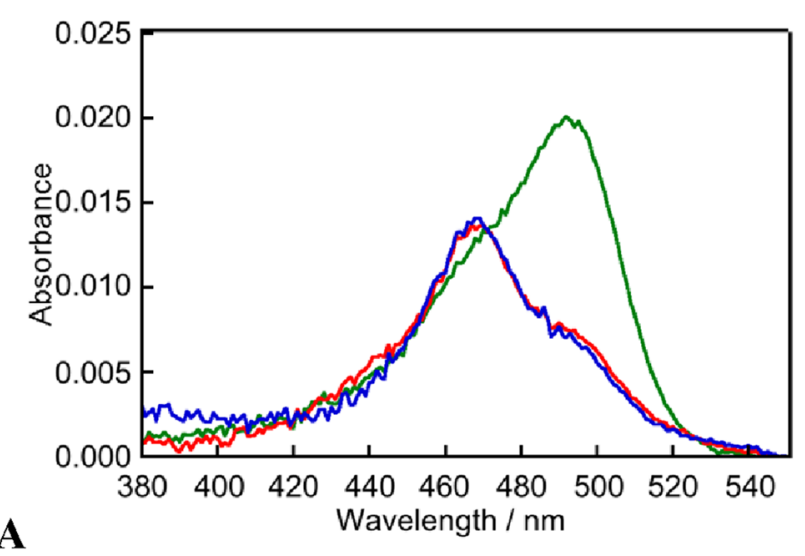

Fig. 2 A Absorption spectra for $0.3 \mu \mathrm{M}$ AO in the absence (green) and presence (blue) of $10 \mu \mathrm{M} \mathrm{CB}[8]$, and after addition of $5 \mu \mathrm{M} \mathrm{OxPt}$ (red). B Fluorescence emission spectra for $0.3 \mu \mathrm{M}$ AO in the presence of $\mathrm{CB}[8]$ before (red line) and after (blue line) the addition of $80 \mu \mathrm{M}$ OxPt. All samples in PBS pH 7.4. The arrow indicates the increase effect of AO (Fig. 3) and OxPt (Fig. 4) on cell viability of HeLa cells cultivated in vitro. For AO, the dark and illuminated conditions were tested using an incubation time of $90 \mathrm{~min}$. In the case of OxPt, two incubation times of $90 \mathrm{~min}$ and $24 \mathrm{~h}$ were tested to assess cytotoxicity. From these experiments, we chose the concentrations of $0.3 \mu \mathrm{M}$ for $\mathrm{AO}$ and $5 \mu \mathrm{M}$ for $\mathrm{OxPt}$, which achieve close to $50 \%$ cytotoxicity, for the following experiments where both compounds were used in combination. Using numerical analysis, we calculated the mole fraction of each species present in the mixture considering all the equilibria involved and the values of the binding constants (see Table S1 and Fig. S3 in the supporting information) $[35,54]$. According to these calculations, in a mixture containing $0.3 \mu \mathrm{M} \mathrm{AO}, 5 \mu \mathrm{M} \mathrm{OxPt}$ and $10 \mu \mathrm{M} \mathrm{CB}[8], 93 \%$ of OxPt and $99 \%$ of AO are complexed with $\mathrm{CB}$ [8] (1:1 stoichiometry in both cases). For the latter, the presence of the 2:1 complex is negligible at these concentrations.

The cytotoxicity (dark) and phototoxicity (light) of the different complexes were evaluated at different incubation regimes. First, the cells were pre-incubated with the OxPt@CB[8] complex for 24 h, and afterwards, the cells were incubated with $\mathrm{AO}$ in the presence of $\mathrm{CB}$ [8] for $90 \mathrm{~min}$ and later irradiated for $15 \mathrm{~min}$ at $520 \mathrm{~nm}$. The results showed that the pre-treatment with the OxPt@ $\mathrm{CB}$ [8] complex alone decreased about $50-60 \%$ of the cell viability, while the incubation/irradiation of $\mathrm{AO}$ in the presence of $\mathrm{CB}$ [8] by itself decreased about $40 \%$ of the cell viability (Fig. 5). However, in the combined treatment, there was no increment in cytotoxicity/phototoxicity compared to OxPt@CB[8]. Fluorescence microscopy experiments showed evident cell damage after the OxPt@ $\mathrm{CB}[8]$ treatment, thus not allowing $\mathrm{AO}$ incorporation (see

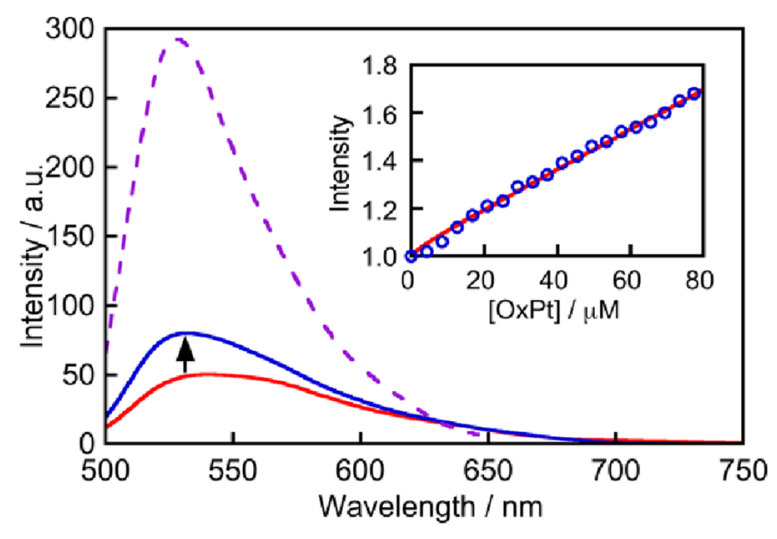

in fluorescence emission after the addition of OxPt. The emission spectra for $0.3 \mu \mathrm{M}$ AO (purple dashed line) are shown as a reference. Inset: fluorescence intensity at $525 \mathrm{~nm}$ upon addition of increasing concentrations of $\mathrm{OxPt}$ 

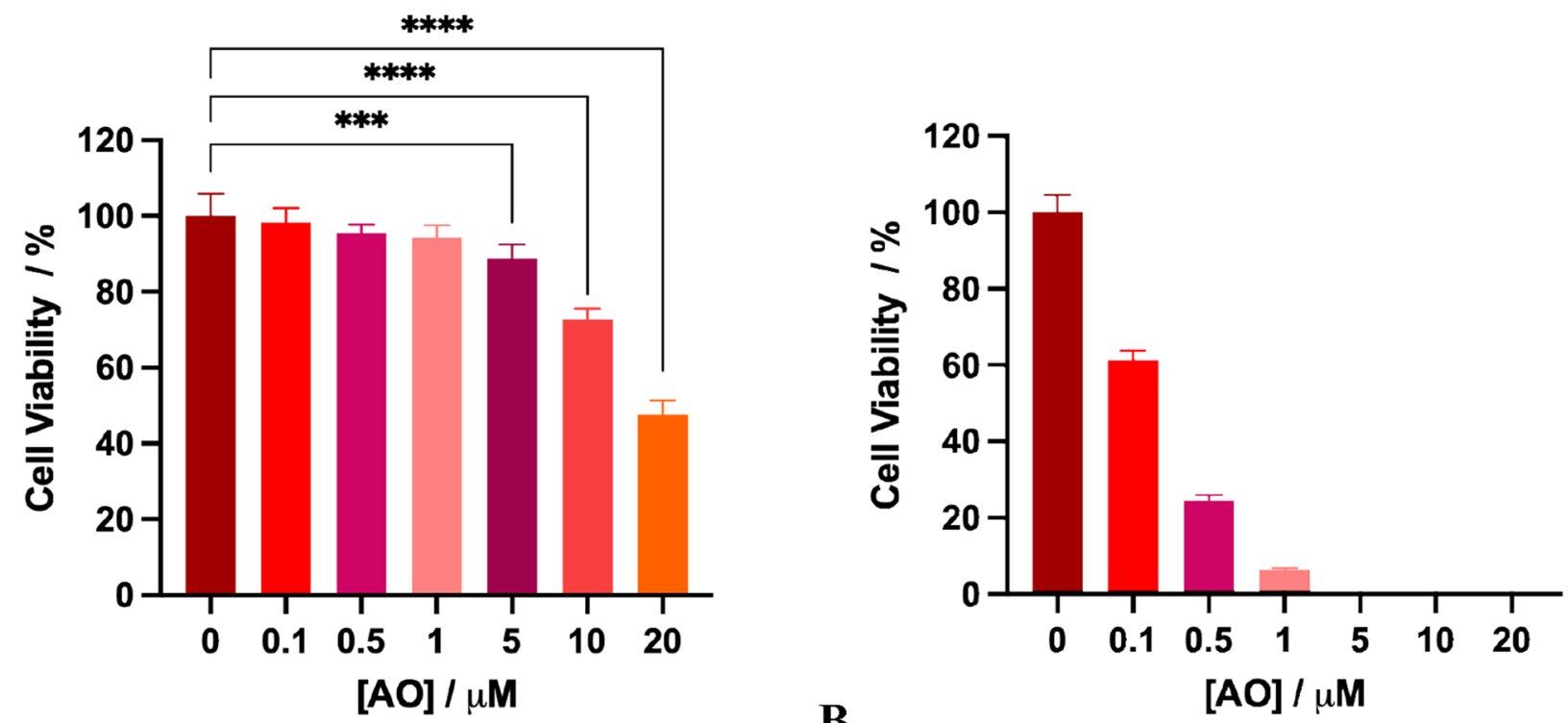

Fig. 3 A Dark toxicity and B phototoxicity of AO on Hela cells. Incubation time of $90 \mathrm{~min}$ and irradiated at $520 \mathrm{~nm}$ for $15 \mathrm{~min}$. Significance of $p<0.05$

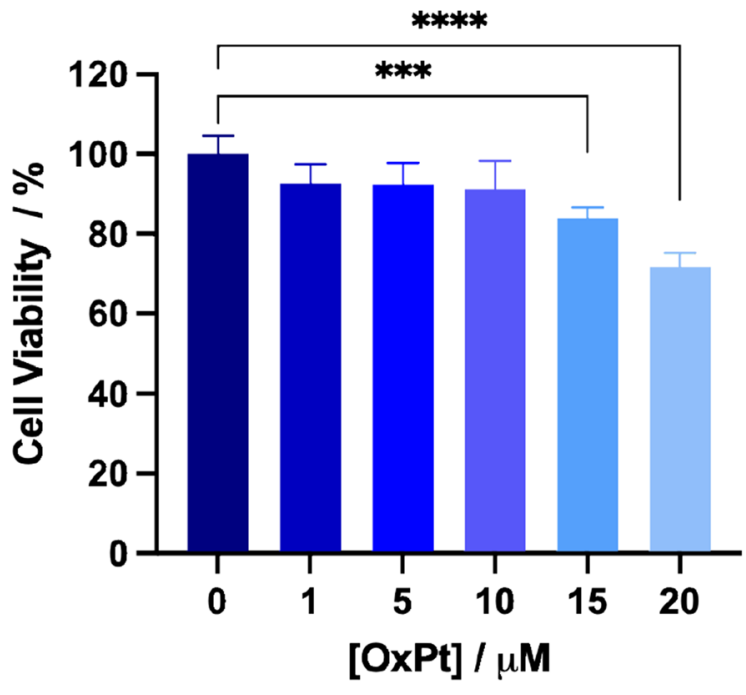

A

B

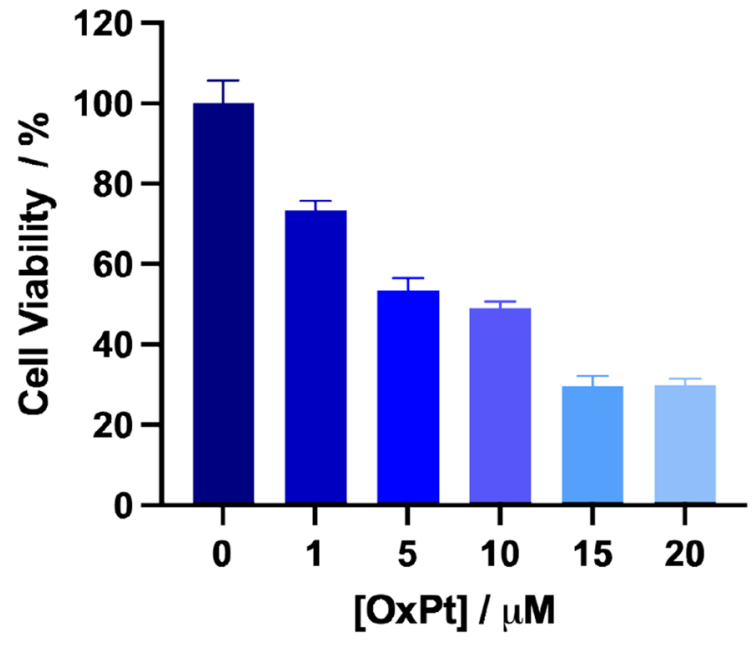

Fig. 4 OxPt cytotoxicity on Hela cells. Incubation with the drug for A 90 min and B 24 h. Significance of $p<0.05$

Fig. S4 in the supplementary information). This explains why no phototoxic effect is evident after irradiation. It is important to note that control experiments with $\mathrm{CB}$ [8] alone showed some cytotoxicity for $24 \mathrm{~h}$ incubation, but not for shorter periods (see Fig. S5 in the supplementary information). Therefore, the cytotoxicity observed with the OxPt@CB[8] complex arises mainly from the release of the drug inside the cells. Moreover, the fact that the OxPt@CB[8] complex shows similar cytotoxicity to free $\mathrm{OxPt}$ at the same conditions suggests that the drug is being released inside the cell.
On a different treatment regime, when both $\mathrm{OxPt}$ and $\mathrm{AO}$ were co-incubated in the presence of $\mathrm{CB}[8]$ with the cells for 90 min, the results showed that the OxPt@CB[8] complex alone was not cytotoxic within this short incubation time, while $\mathrm{AO}$ irradiated in the presence of $\mathrm{CB}[8]$ killed about $40 \%$ of the cells. Surprisingly, the combined treatment killed $70 \%$ of the cells, adding up to an extra $30 \%$ effectiveness in tumoral cell killing (Fig. 6). The combined treatment at short incubation times significantly enhanced cytotoxicity/phototoxicity compared to both treatments separately, suggesting a cooperative behaviour due to co-encapsulation. Interestingly, 


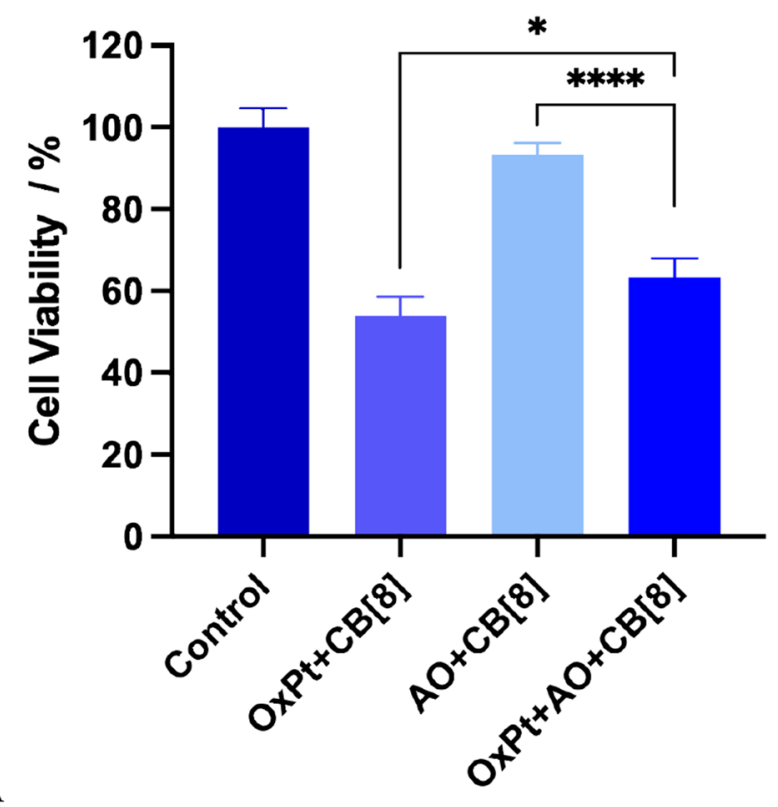

Fig. 5 A Dark toxicity and B phototoxicity on HeLa cells when treated with $\mathrm{AO}+\mathrm{CB}[8], \mathrm{OxPt}+\mathrm{CB}[8]$ or a mixture of $\mathrm{AO}+\mathrm{OxPt}+\mathrm{CB}[8]$. Pre-incubation of $\mathrm{OxPt}+\mathrm{CB}[8]$ for $24 \mathrm{~h}$, fol-

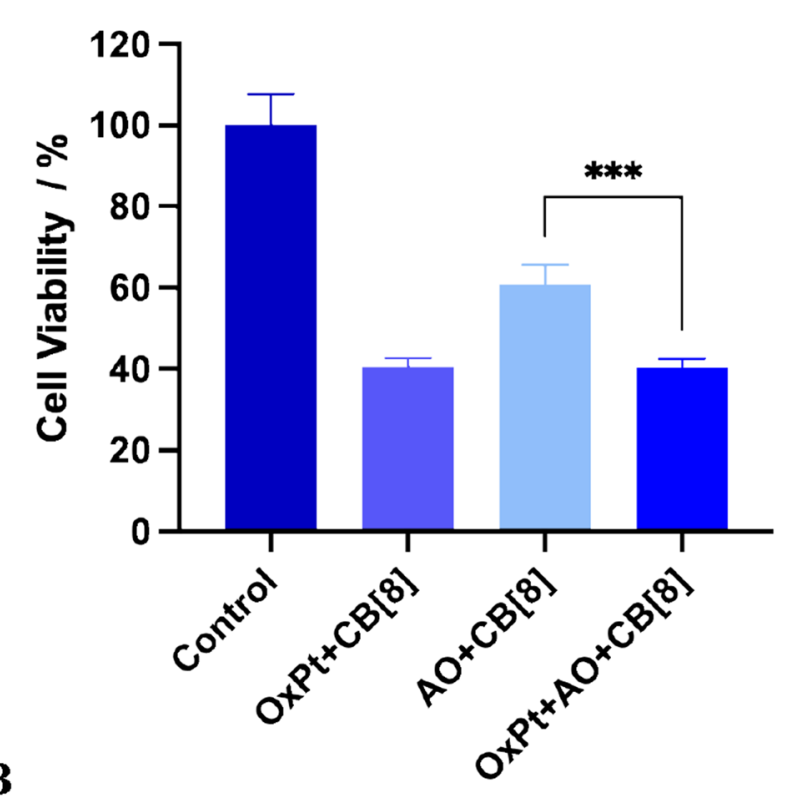

lowed by incorporation of $\mathrm{AO}+\mathrm{CB}[8]$ for $90 \mathrm{~min}$ and irradiation for $15 \mathrm{~min}$ with $520 \mathrm{~nm}$ LEDs. Significance of $p<0.05$

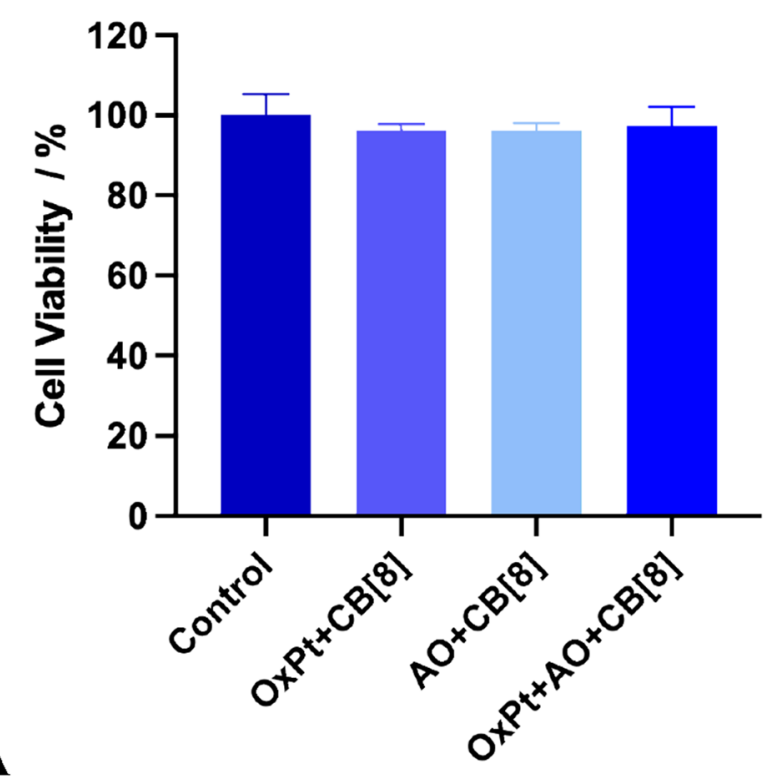

B

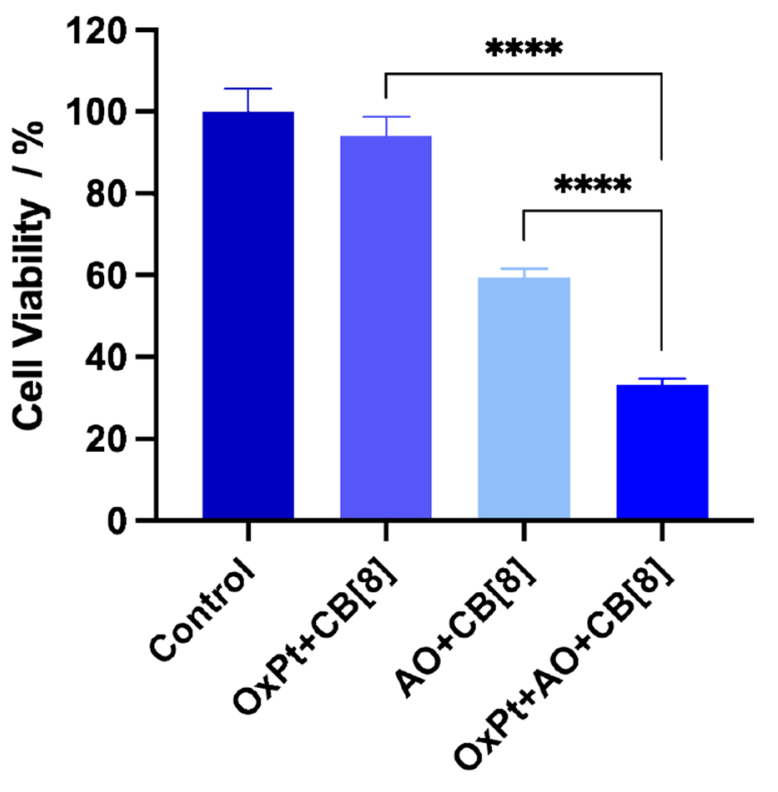

Fig. 6 A Dark toxicity and $\mathbf{B}$ phototoxicity on HeLa cells when treated with $\mathrm{AO}+\mathrm{CB}[8], \mathrm{OxPt}+\mathrm{CB}[8]$ or a mixture of $\mathrm{AO}+\mathrm{OxPt}+\mathrm{CB}[8]$. $\mathrm{Co}-$ incubation for $90 \mathrm{~min}$ and irradiation for $15 \mathrm{~min}$ with $520 \mathrm{~nm}$ LEDs. Significance of $p<0.05$

in vivo studies for the use of a porphyrin-liposome loaded with doxorubicin show better results at short drug-light intervals $[55,56]$. The enhancement effect observed herein does not necessarily prove that there is synergy between both treatments. This requires a detailed examination of the outcomes at different concentrations of OxPt and AO@
$\mathrm{CB}[8]$, and different light doses. Also, in vivo experiments are needed for future work.

Given that OxPt also binds strongly to $\mathrm{CB}[7][3,47-49$, 53], and its biocompatibility [57, 58], we tested the effect of the OxPt@CB[7] complex in cell cytotoxicity in combination with $\mathrm{AO} @ \mathrm{CB}[8]$. In this case, no increment in cell 
killing was observed compared to the AO@ $\mathrm{CB}[8]$ complex alone (see Fig. S6 in the supporting information). These results indicate that the potentiation effect observed with the OxPt@CB[8] complex is dependent on the macrocycle. One possibility is that the OxPt@CB[7] complex might be more stable inside the cells compared to the OxPt@CB[8] complex. The evidence in the literature is variable for different cell lines in vitro. Initial studies in A549, SKOV-3, SKMEL-2, XF-498 and HCT-15 showed decrease cytotoxicity [47], the same for L1210 cell line [48]. Meanwhile, more recent studies have shown greater cytotoxicity in B16 and K562 cell lines [49]. In our experiments, the cytotoxicity in HeLa cells was significantly reduced for the OxPt@CB[7] supporting a higher stability (see Fig. S7 in the supporting information).

Since AO is fluorescent, we could detect the fluorescence emission of the photosensitizer inside live cells, as shown in Fig. 7. Control experiments in the absence of AO did not show any background fluorescence (Fig. 7a). Meanwhile, in the presence of free $\mathrm{AO}$ (Fig. 7b), AO in the presence of $\mathrm{CB}$ [8] (Fig. 7c) or a mixture of $\mathrm{AO}$ and $\mathrm{OxPt}$ with $\mathrm{CB}[8]$ (Fig. 7d), Hela cells clearly showed the characteristic fluorescence of the photosensitizer.

At the same experimental conditions, the fluorescence intensity observed for free $\mathrm{AO}$ was higher than that for $\mathrm{AO}$ in the presence of $\mathrm{CB}$ [8] (Fig. 7b, c), which could be attributed in principle to their different fluorescence quantum yields [33, 35]. This was reported by García, Scaiano and collaborators, where they proposed that the photosensitizer complex is maintained inside the cells [43]. However, when cell uptake was measured quantitatively, it is evident that free $\mathrm{AO}$ is taken up by the cells more efficiently than the AO@CB [8] complex (Fig. 8), contributing to a higher fluorescence emission. In this context, the presence of OxPt does

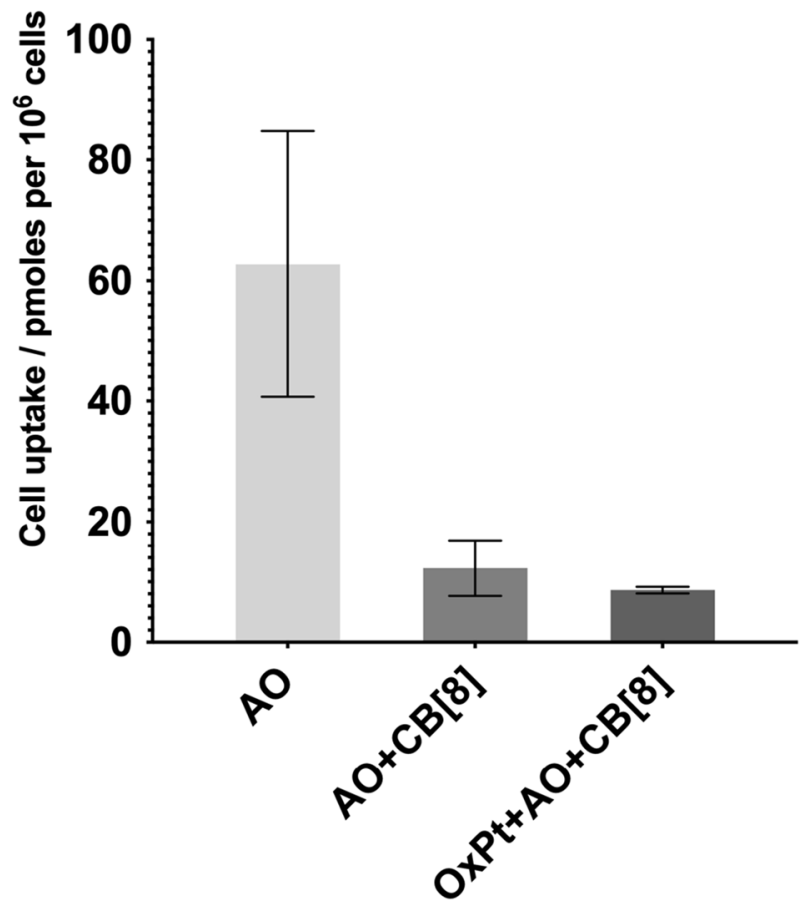

Fig. 8 Cell uptake for free $\mathrm{AO}, \mathrm{AO}+\mathrm{CB}[8]$ or $\mathrm{AO}+\mathrm{OxPt}+\mathrm{CB}[8]$ systems. Incubation during $90 \mathrm{~min}$
Fig. 7 HeLa cells fluorescence microscopy images in the absence (a) or presence of $\mathbf{b}$ free $\mathrm{AO}, \mathbf{c} \mathrm{AO}+\mathrm{CB}[8]$ or $\mathbf{d}$ $\mathrm{AO}+\mathrm{OxPt}+\mathrm{CB}[8]$. Incubation during $90 \mathrm{~min}$. Excitation at $469 \mathrm{~nm}$ and emission at $525 \mathrm{~nm}$

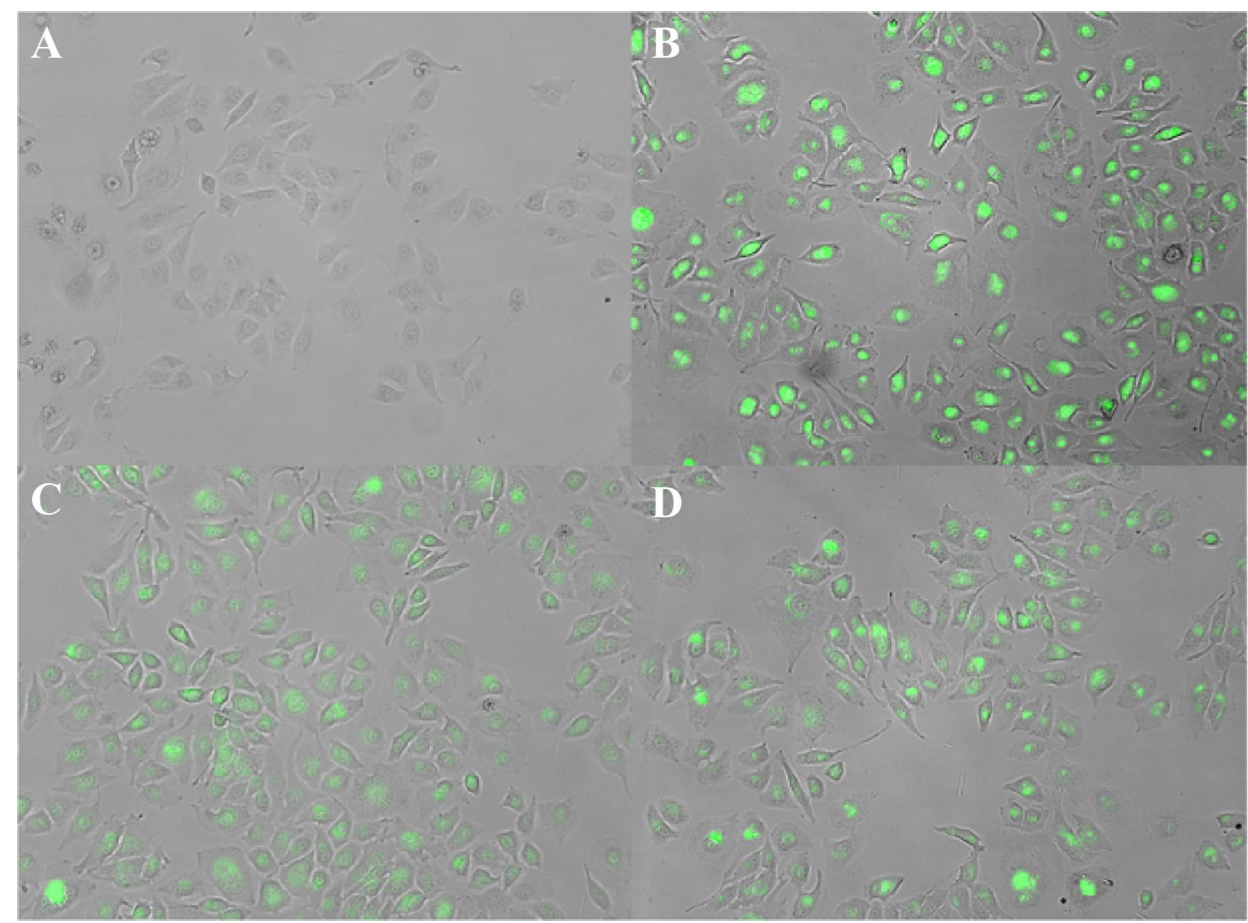


not modify the incorporation of the AO@ $\mathrm{CB}[8]$ complex to the cells.

It is interesting to note that in the case of the co-incubation of $\mathrm{AO}$ and $\mathrm{OxPt}$ with $\mathrm{CB}[8]$, although cell uptake is the same as in the absence of OxPt (Fig. 8), the fluorescence intensity appears higher when measured in live cells (Fig. 7d). This points to a possible release of $\mathrm{AO}$ from the cavity of $\mathrm{CB}[8]$ intracellularly. One possibility is that some biomolecules inside the cell bind to the macrocycle inducing the release of AO such as amino acids, peptides and proteins [59]. The same behaviour was reported for a toluidine blue derivative complexed with $\mathrm{CB}$ [8] [15]. It must be pointed out that this phenomenon has not been measured directly due to the complexity of understanding $\mathrm{CB}[n]$ s complexes release kinetics in live cells. However, pharmacokinetics analysis of somedrug@CB[7] complexes in vivo strongly suggests that the release of the drugs is modified by encapsulation in the macrocycle, leading to a change in biodistribution [60-62].

A possible release of $\mathrm{AO}$ intracellularly can influence the photoactivity of the photosensitizer. When the phototoxicities of free AO and the AO@CB[8] complex were compared at the same concentrations, AO showed higher phototoxicity (Fig. S8 in the supplementary information). This is in agreement with the higher cell uptake of AO compared to its complex. Nonetheless, this result contradicts the expected trend based on singlet oxygen generation efficiencies for the free photosensitizer and its CB[8] complexes. Singlet oxygen generated through type II mechanism (energy transfer) is thought to be one of the main species inducing cell death during PDT $[13,21]$. The quantum yield of singlet oxygen formation for $\mathrm{AO}$ is 0.18 , while that for the AO@ $\mathrm{CB}[8]$ complex is 0.31 [41]. Not only cell uptake is important, we demonstrated previously that the photooxidative effect of photosensitizer@CB $[n]$ complexes can depend highly on their interactions with proteins pointing to an important role of the type I mechanism (electron transfer) [41]. In fact, AO showed higher photooxidation of a model albumin protein compared to the AO@CB[8] complex due to binding to the protein [41]. Therefore, there could be more favorable interactions between the free photosensitizer and cellular components compared to the AO@CB[8] complex, giving rise to mixed-type I-type II photoprocesses explaining its higher photoactivity.

\section{Conclusions}

We have shown that by co-encapsulating $\mathrm{AO}$ and OxPt in $\mathrm{CB}$ [8], cooperative cell death can be achieved at short incubation times. Meanwhile, pre-incubation with the OxPt@ CB[8] complex led to no increase in phototoxicity by AO@ $\mathrm{CB}[8]$. A stepwise binding process for $\mathrm{AO}$ with $\mathrm{CB}[8]$ was corroborated by ITC analysis, showing negative cooperativity for the binding of the second $\mathrm{AO}$ molecule. Furthermore, evidence for the formation of the OxPt@CB[8] complex is reported for the first time, with a binding constant comparable to previously reported OxPt@CB[7] complex. However, when OxPt@CB[8] is switched for OxPt@CB[7], no enhancement in cell death is observed. Evidence for the release of $\mathrm{AO}$ in the presence of OxPt was presented, which could enhance cell phototoxicity. In this case, AO acts through mixed-type I-type II photoprocesses with proteins. These results are interesting for the use of cucurbit $[n]$ uril-based supramolecular complexes in chemophototherapy applications, although synergism must be proven by varying the drugs and light doses and corroborated in vivo in the future.

Supplementary Information The online version contains supplementary material available at https://doi.org/10.1007/s43630-022-00174-7.

Acknowledgements We thank ANID for the financial support though Fondecyt No 1210583, Fondequip EQM160042 and EQM170120. DF thanks VRI for PUENTE UC 014/2020 research Grant and DIPOG for financial support. Special thanks to Benjamín Pérez-López for helping with the cell culture preparation.

\section{Declarations}

Conflict of interest The authors declare no competing interests.

\section{References}

1. Zhou, J., Yu, G. C., \& Huang, F. H. (2017). Supramolecular chemotherapy based on host-guest molecular recognition: A novel strategy in the battle against cancer with a bright future. Chemical Society Reviews, 46, 7021-7053.

2. Fahmy, S. A., Brussler, J., Alawak, M., El-Sayed, M. M. H., Bakowsky, U., \& Shoeib, T. (2019). Chemotherapy based on supramolecular chemistry: A promising strategy in cancer therapy. Pharmaceutics, 11.

3. Chen, Y. Y., Huang, Z. H., Zhao, H. Y., Xu, J. F., Sun, Z. W., \& Zhang, X. (2017). Supramolecular chemotherapy: Cooperative enhancement of antitumor activity by combining controlled release of oxaliplatin and consuming of spermine by cucurbit[7] uril. ACS Applied Materials \& Interfaces, 9, 8602-8608.

4. Wu, D., Li, Y., Yang, J., Shen, J., Zhou, J., Hu, Q., Yu, G., Tang, G., \& Chen, X. (2017). Supramolecular nanomedicine constructed from cucurbit[8]uril-based amphiphilic brush copolymer for cancer therapy. ACS Applied Materials \& Interfaces, 9, 44392-44401.

5. Hao, Q., Chen, Y. Y., Huang, Z. H., Xu, J. F., Sun, Z. W., \& Zhang, X. (2018). Supramolecular chemotherapy: Carboxylated Pillar[6]arene for decreasing cytotoxicity of oxaliplatin to normal cells and improving its anticancer bioactivity against colorectal cancer. ACS Applied Materials \& Interfaces, 10, 5365-5372.

6. Webber, M. J., \& Langer, R. (2017). Drug delivery by supramolecular design. Chemical Society Reviews, 46, 6600-6620.

7. Wang, L., Li, L. L., Fan, Y. S., \& Wang, H. (2013). Host-guest supramolecular nanosystems for cancer diagnostics and therapeutics. Advanced Materials, 25, 3888-3898. 
8. D. Das, K. I. Assaf and W. M. Nau, Applications of Cucurbiturils in Medicinal Chemistry and Chemical Biology, Frontiers in Chemistry, 2019, 7.

9. Saleh, N., Ghosh, I., \& Nau, W. M. (2013). Cucurbiturils in drug delivery and for biomedical applications. In H.-J. Schneider (Ed.), Supramolecular systems in biomedical fields (pp. 164-212). Royal Society of Chemistry.

10. Rajora, M. A., Lou, J. W. H., \& Zheng, G. (2017). Advancing porphyrin's biomedical utility via supramolecular chemistry. Chemical Society Reviews, 46, 6433-6469.

11. Li, X., Lee, S., \& Yoon, J. (2018). Supramolecular photosensitizers rejuvenate photodynamic therapy. Chemical Society Reviews, 47, 1174-1188.

12. Yang, K., Zhang, Z., Du, J., Li, W., \& Pei, Z. (2020). Hostguest interaction based supramolecular photodynamic therapy systems: A promising candidate in the battle against cancer. Chemical Communications, 56, 5865-5876.

13. Dabrowski, J. M., \& Arnaut, L. G. (2015). Photodynamic therapy (PDT) of cancer: From local to systemic treatment. Photochemical \& Photobiological Sciences, 14, 1765-1780.

14. Robinson-Duggon, J., Perez-Mora, F., Dibona-Villanueva, L., \& Fuentealba, D. (2018). Potential applications of cucurbit[n]urils inclusion complexes in photodynamic therapy. Israel Journal of Chemistry, 58, 199-214.

15. Wang, X. Q., Lei, Q., Zhu, J. Y., Wang, W. J., Cheng, Q., Gao, F., Sun, Y. X., \& Zhang, X. Z. (2016). Cucurbit[8]uril regulated activatable supramolecular photosensitizer for targeted cancer imaging and photodynamic therapy. ACS Applied Materials \& Interfaces, 8, 22892-22899.

16. Robinson-Duggon, J., Perez-Mora, F., Valverde-Vasquez, L., Cortes-Arriagada, D., De la Fuente, J. R., Gunther, G., \& Fuentealba, D. (2017). Supramolecular reversible on-off switch for singlet oxygen using cucurbit[n]uril inclusion complexes. Journal of Physical Chemistry C, 121, 21782-21789.

17. Luo, D. D., Carter, K. A., Miranda, D., \& Lovell, J. F. (2017). Chemophototherapy: An emerging treatment option for solid tumors. Advanced Science, 4.

18. Spring, B. Q., Rizvi, I., Xu, N., \& Hasan, T. (2015). The role of photodynamic therapy in overcoming cancer drug resistance. Photochemical \& Photobiological Sciences, 14, 1476-1491.

19. Moser, J. G. (1998). Photodynamic tumor therapy: 2nd and $3 \mathrm{rd}$ generation photosensitizers. Harwood Academic Publishers.

20. Detty, M. R., Gibson, S. L., \& Wagner, S. J. (2004). Current clinical and preclinical photosensitizers for use in photodynamic therapy. Journal of Medicinal Chemistry, 47, 3897-3915.

21. Hamblin, M. R., \& Mróz, P. (2008). Advances in photodynamic therapy. Basic, translational, and clinical. Artech House.

22. O'connor, A. E., Gallagher, W. M., \& Byrne, A. T. (2009). Porphyrin and nonporphyrin photosensitizers in oncology: Preclinical and clinical advances in photodynamic therapy. Photochemistry and Photobiology, 85, 1053-1074.

23. Zhen, Z. P., Tang, W., Chuang, Y. J., Todd, T., Zhang, W. Z., Lin, X., Niu, G., Liu, G., Wang, L. C., Pan, Z. W., Chen, X. Y., \& Xie, J. (2014). Tumor vasculature targeted photodynamic therapy for enhanced delivery of nanoparticles. ACS Nano, 8 , 6004-6013.

24. Anand, S., Rollakanti, K. R., Brankov, N., Brash, D. E., Hasan, T., \& Maytin, E. V. (2017). Fluorouracil enhances photodynamic therapy of squamous cell carcinoma via a p53-independent mechanism that increases protoporphyrin IX levels and tumor cell death. Molecular Cancer Therapeutics, 16, 1092-1101.

25. Broekgaarden, M., Rizvi, I., Bulin, A. L., Petrovic, L., Goldschmidt, R., Massodi, I., Celli, J. P., \& Hasan, T. (2018). Neoadjuvant photodynamic therapy augments immediate and prolonged oxaliplatin efficacy in metastatic pancreatic cancer organoids. Oncotarget, 9, 13009-13022.
26. Luo, D., Geng, J., Li, N., Carter, K. A., Shao, S., Atilla-Gokcumen, G. E., \& Lovell, J. F. (2017). Vessel-targeted chemophototherapy with cationic porphyrin-phospholipid liposomes. Molecular Cancer Therapeutics, 16, 2452-2461.

27. Liu, X. L., Dong, X., Yang, S. C., Lai, X., Liu, H. J., Gao, Y., Feng, H. Y., Zhu, M. H., Yuan, Y., Lu, Q., Lovell, J. F., Chen, H. Z., \& Fang, C. (2021). Biomimetic liposomal nanoplatinum for targeted cancer chemophototherapy. Advancement of Science, 8 , 2003679.

28. Wang, H. H., Fu, Z. G., Li, W., Li, Y. X., Zhao, L. S., Wen, L., Zhang, J. J., \& Wen, N. (2019). The synthesis and application of nano doxorubicin-indocyanine green matrix metalloproteinaseresponsive hydrogel in chemophototherapy for head and neck squamous cell carcinoma. International Journal of Nanomedicine, 14, 623-638.

29. Zhang, C., Wang, Y., Zhao, Y., Liu, H., Zhao, Y., Li, X., \& Lin, Q. (2019). Biodegradable micelles for NIR/GSH-triggered chemophototherapy of cancer. Nanomaterials, 9.

30. Kwon, Y. M., Je, J. Y., Cha, S. H., Oh, Y., \& Cho, W. H. (2019). Synergistic combination of chemophototherapy based on temozolomide/ICGloaded iron oxide nanoparticles for brain cancer treatment. Oncology Reports, 42, 1709-1724.

31. Wang, X., Li, X., Mao, Y., Wang, D., Zhao, Q., \& Wang, S. (2019). Multi-stimuli responsive nanosystem modified by tumortargeted carbon dots for chemophototherapy synergistic therapy. Journal of Colloid and Interface Science, 552, 639-650.

32. Zhu, L., Gao, D., Xie, L., Dai, Y., \& Zhao, Q. (2020). NIR IIexcited and $\mathrm{pH}$-responsive ultrasmall nanoplatform for deep optical tissue and drug delivery penetration and effective cancer chemophototherapy. Molecular Pharmaceutics, 17, 3720-3729.

33. Montes-Navajas, P., Corma, A., \& Garcia, H. (2008). Complexation and fluorescence of tricyclic basic dyes encapsulated in cucurbiturils. ChemPhysChem, 9, 713-720.

34. Yi, S., \& Kaifer, A. E. (2011). Determination of the purity of cucurbit[n]uril $(n=7,8)$ host samples. Journal of Organic Chemistry, 76, 10275-10278.

35. Scholtbach, K., Venegas, I., Bohne, C., \& Fuentealba, D. (2015). Time-resolved fluorescence anisotropy as a tool to study guestcucurbit[n]uril-protein ternary supramolecular interactions. Photochemical \& Photobiological Sciences, 14, 842-852.

36. Buurma, N. J., \& Haq, I. (2008). Calorimetric and spectroscopic studies of Hoechst 33258: Self-association and binding to noncognate DNA. Journal of Molecular Biology, 381, 607-621.

37. Saeed, I. Q., \& Buurma, N. J. (2019). Analysis of isothermal titration calorimetry data for complex interactions using I2CITC. Microcalorimetry of Biological Molecules, 1964, 169-183.

38. Buurma, N. J., \& Haq, I. (2007). Advances in the analysis of isothermal titration calorimetry data for ligand-DNA interactions. Methods, 42, 162-172.

39. Blears, D. J., \& Danyluk, S. S. (1966). The aggregation of acridine orange in aqueous solution1. Journal of the American Chemical Society, 88, 1084-1085.

40. Villarroel-Lecourt, G., Carrasco-Carvajal, J., Andrade-Villalobos, F., Solís-Egaña, F., Merino-San Martín, I., Robinson-Duggon, J., \& Fuentealba, D. (2018). Encapsulation of chemotherapeutic drug melphalan in cucurbit[7]uril: Effects on its alkylating activity, hydrolysis, and cytotoxicity. ACS Omega, 3, 8337-8343.

41. Caceres, J., Robinson-Duggon, J., Tapia, A., Paiva, C., Gomez, M., Bohne, C., \& Fuentealba, D. (2017). Photochemical behavior of biosupramolecular assemblies of photosensitizers, cucurbit[n] urils and albumins. Physical Chemistry Chemical Physics: PCCP, 19, 2574-2582.

42. Li, F. S., Xu, Y. Q., Li, H. J., Wang, C. X., Lu, A. P., \& Sun, S. G. (2014). Discrimination of DNA from RNA with the host-guest complexes of tricyclic basic dyes and cucurbit[8]uril. New Journal of Chemistry, 38, 1396-1400. 
43. Montes-Navajas, P., Gonzalez-Bejar, M., Scaiano, J. C., \& Garcia, H. (2009). Cucurbituril complexes cross the cell membrane. Photochemical \& Photobiological Sciences, 8, 1743-1747.

44. Robinson, B. H., Löffler, A., \& Schwarz, G. (1973). Thermodynamic behaviour of acridine orange in solution. Model system for studying stacking and charge-effects on self-aggregation. Journal of the Chemical Society, Faraday Transactions, 69, 56-69.

45. Thordarson, P. (2012). Binding constants and their measurement. In P. A. Gale \& J. W. Steed (Eds.), Supramolecular chemistry: From molecules to nanomaterials. Berlin: Wiley.

46. De Falco, V., Napolitano, S., Roselló, S., Huerta, M., Cervantes, A., Ciardiello, F., \& Troiani, T. (2019). How we treat metastatic colorectal cancer. ESMO Open, 4, e000813.

47. Jeon, Y. J., Kim, S. Y., Ko, Y. H., Sakamoto, S., Yamaguchi, K., \& Kim, K. (2005). Novel molecular drug carrier: Encapsulation of oxaliplatin in cucurbit[7]uril and its effects on stability and reactivity of the drug. Organic \& Biomolecular Chemistry, 3, 2122-2125.

48. Cao, L. P., Hettiarachchi, G., Briken, V., \& Isaacs, L. (2013). Cucurbit[7]uril containers for targeted delivery of oxaliplatin to cancer cells. Angewandte Chemie International Edition, 52, 12033-12037.

49. Pashkina, E., Aktanova, A., Mirzaeva, I., Kovalenko, E., Andrienko, I., Knauer, N., Pronkina, N., \& Kozlov, V. (2021). The Effect of cucurbit[7]uril on the antitumor and immunomodulating properties of oxaliplatin and carboplatin. International Journal of Molecular Science, 22.

50. Huang, X., Zhou, H., Jiao, R., Liu, H., Qin, C., Xu, L., \& Chen, Y. (2021). Supramolecular chemotherapy: Host-guest complexes of heptaplatin-cucurbit[7]uril toward colorectal normal and tumor cells. Langmuir, 37, 5475-5482.

51. Suvitha, A., Venkataramanan, N. S., Mizuseki, H., Kawazoe, Y., \& Ohuchi, N. (2010). Theoretical insights into the formation, structure, and electronic properties of anticancer oxaliplatin drug and cucurbit[n]urils $\mathrm{n}=5$ to 8 . Journal of Inclusion Phenomena and Macrocyclic Chemistry, 66, 213-218.

52. Venkataramanan, N. S., Ambigapathy, S., Mizuseki, H., \& Kawazoe, Y. (2012). Theoretical prediction of the complexation behaviors of antitumor platinum drugs with cucurbiturils. The Journal of Physical Chemistry B, 116, 14029-14039.

53. Wu, H., Chen, H., Tang, B. H., Kang, Y. T., Xu, J. F., \& Zhang, X. (2020). Host-Guest interactions between oxaliplatin and
cucurbit[7]uril/Cucurbit[7]uril derivatives under pseudo-physiological conditions. Langmuir, 36, 1235-1240.

54. Tang, H., Fuentealba, D., Ko, Y. H., Selvapalam, N., Kim, K., \& Bohne, C. (2011). Guest binding dynamics with cucurbit[7]uril in the presence of cations. Journal of the American Chemical Society, 133, 20623-20633.

55. Luo, D., Carter, K. A., Geng, J., He, X., \& Lovell, J. F. (2018). Short drug-light intervals improve liposomal chemophototherapy in mice bearing MIA PaCa-2 Xenografts. Molecular Pharmaceutics, 15, 3682-3689.

56. Luo, D., Carter, K. A., Molins, E. A. G., Straubinger, N. L., Geng, J., Shao, S., Jusko, W. J., Straubinger, R. M., \& Lovell, J. F. (2019). Pharmacokinetics and pharmacodynamics of liposomal chemophototherapy with short drug-light intervals. Journal of Controlled Release, 297, 39-47.

57. Zhang, X. J., Xu, X. Q., Li, S. K., Wang, L. H., Zhang, J. X., \& Wang, R. B. (2018). A systematic evaluation of the biocompatibility of cucurbit[7]uril in mice. Scientific Reports, 8 .

58. Uzunova, V. D., Cullinane, C., Brix, K., Nau, W. M., \& Day, A. I. (2010). Toxicity of cucurbit[7]uril and cucurbit[8]uril: An exploratory in vitro and in vivo study. Organic \& Biomolecular Chemistry, 8, 2037-2042.

59. Urbach, A. R., \& Ramalingam, V. (2011). Molecular recognition of amino acids, peptides, and proteins by cucurbit[n]uril receptors. Israel Journal of Chemistry, 51, 664-678.

60. Plumb, J. A., Venugopal, B., Oun, R., Gomez-Roman, N., Kawazoe, Y., Venkataramanan, N. S., \& Wheate, N. J. (2012). Cucurbit[7]uril encapsulated cisplatin overcomes cisplatin resistance via a pharmacokinetic effect. Metallomics, 4, 561-567.

61. Ma, W. J., Chen, J. M., Jiang, L., Yao, J., \& Lu, T. B. (2013). The delivery of triamterene by cucurbit[7]uril: Synthesis, structures and pharmacokinetics study. Molecular Pharmaceutics, 10, 4698-4705.

62. Li, F. F., Gorle, A. K., Ranson, M., Vine, K. L., Kinobe, R., Feterl, M., Warner, J. M., Keene, F. R., Collins, J. G., \& Day, A. I. (2017). Probing the pharmacokinetics of cucurbit[7, 8 and 10] uril: And a dinuclear ruthenium antimicrobial complex encapsulated in cucurbit[10]uril. Organic \& Biomolecular Chemistry, 15, $4172-4179$.

\section{Authors and Affiliations}

\section{Fresia Solis-Egaña ${ }^{1} \cdot$ Nicole Lavín-Urqueta ${ }^{1} \cdot$ Daniel Guerra Díaz ${ }^{1} \cdot$ Nory Mariño-Ocampo $^{1} \cdot$ Mario A. Faúndez $^{2}$. Denis Fuentealba' ${ }^{1}$ (i)}

1 Laboratorio de Química Supramolecular y Fotobiología, Departamento de Química Física, Escuela de Química, Facultad de Química y de Farmacia, Pontificia Universidad Católica de Chile, Vicuña Mackenna 4860, Macul, Santiago, Chile
2 Escuela de Farmacia, Facultad de Química y de Farmacia, Pontificia Universidad Católica de Chile, Vicuña Mackenna 4860, Macul, Santiago, Chile 